\title{
A Prostituta Japonesa e o Homem de BAÇORÁ: O FRACASSO DO LEITOR COMO ESTRATÉGIA TEXTUAL NA FiCÇÃO DE VALÊNCIO XAVIER*
}

\author{
The Japanese prostitute and the man from Basra: the \\ failure of the reader as a textual strategy in \\ Valêncio Xavier's fiction
}

Francisco R. S. Innocêncio**

\section{SOBRE O FRACASSO DO LEITOR}

Para Vincent Jouve, o texto literário é estruturalmente incompleto e por isso "não pode abrir mão da contribuição do leitor" para obter sentido (JOUVE, 2002, p. 62). Segundo ele, "o texto [...] pode apenas programar a leitura: é o leitor que deve concretizá-la” (JOUVE, 2002,, p. 74). Em outras palavras, um texto tomado como partitura, e para que ela seja executada, o leitor precisa usar de estratégias de leitura a fim de tentar recuperar seus sentidos, quer o programado pelo autor no momento da escrita, quer os novos sentidos possíveis, resultantes da interação entre o texto e seus diferentes leitores. Como a música do jazz, em que a partitura original é enriquecida de acordes, referências e improvisos a cada nova execução, o texto escrito também adquire novos significados a cada nova leitura.

Entre as ferramentas usadas pelo leitor, interessa-nos destacar alguns dos recursos de leitura mencionados por Jouve. O primeiro deles é o uso daquilo que Eco (apud JOUVE, 2002, p. 79) chama de "dicionário de base" e "regras de correferência", ou seja, as informações que compõem sua visão de mundo - ideológica - e que permitem que ele faça uso da "capacidade de interpretar o 'hipercódigo retórico e estilístico', uma familiaridade com os 'cenários comuns e intertextuais'” (JOUVE, 2002, p.

Agradecimentos: A Jefferson S. Kimura e Cristina Katayoshi, pelas informações sobre a escrita japonesa e pelas traduções das falas da prostituta japonesa. À profa ${ }^{a}$. Marta Morais da Costa, por suas observações e sugestões ao texto.

" Mestre em Letras pela UFPR. 
79), ou seja, o conhecimento prévio - o qual inclui a própria língua em que o texto está escrito - que compõe o repertório do leitor. Quando, porém, se depara com os limites desse conhecimento, o leitor procura "estender" seu repertório, apelando para uma nova estratégia, a da interpretação simbólica (JOUVE, 2002, p. 75). Este jogo de correferências oferecidas ou sonegadas, acessíveis ou remotas, é que faz com que o ato de leitura de um texto literário seja um processo dinâmico, interativo, gerador de significados. Nesse sentido, Umberto Eco vai ainda mais longe quando recorre a seus conceitos de "leitor modelo", ou seja, aquele leitor que é previsto pelas estratégias textuais com que o autor constrói sua narrativa, e "leitor empírico", aquele ser imprevisível que se debruça sobre o texto com a intenção de lê-lo e para cuja leitura não há regras determinantes. Diz ele:

O Leitor Modelo de uma história não é o Leitor Empírico. O leitor empírico é você, eu, qualquer um, quando lemos um texto. Leitores empíricos podem ler de muitas maneiras, e não há lei que lhes diga como ler, porque eles com freqüência se valem do texto como um recipiente para suas próprias paixões, que podem vir de fora do texto, ou as quais o texto pode despertar por acaso (ECO, 2005) ${ }^{1}$.

Eco entende o signo linguístico - e, podemos inferir, por extensão o texto literário - como "campo de estímulos" (ECO, 2000, p. 84). Comentando a estratégia empregada por James Joyce em Finnegans Wake, por exemplo, afirma que a comunicação da mensagem de modo ambíguo influi na sua própria "capacidade de provocação imaginativa" (ECO, 2000, p. 91), o que enriquece o jogo de referências e correferências. Essa concepção do signo linguístico está presente também em Wolfgang Iser, para quem “...os signos lingüísticos do texto, suas estruturas, ganham sua finalidade em razão de sua capacidade de estimular atos, no decorrer dos quais o texto se traduz para a consciência do leitor" (ISER, 2000, p. 10). O texto, portanto, estimula atos que dão origem à sua própria compreensão (ISER, 2000, p. 9).

Este modo de ver o texto literário liga-se o seu conceito de "espaços vazios”, ou seja, os espaços de indeterminação, inerentes à linguagem, à cultura, às estratégias adotadas pelo autor implícito etc., que todo texto apresenta em maior ou menor grau, e que exigem um preenchimento de sentido por parte do leitor. Tal preenchimento, diga-se, obedecerá a diferentes critérios de acordo com as expectativas do leitor, seu universo de referências e correferências pessoais, o campo de conotações que pode ser atingido por ele, sua enciclopédia, enfim, da qual não deve ser esquecido o contexto cultural em que vive. Em A Obra Aberta, Umberto Eco fornece-nos um ótimo exemplo de como as proposições podem exercer função sugestiva, levando

\footnotetext{
1 "The Model Reader of a story is not the Empirical Reader. The empirical reader is you, me, anyone, when we read a text. Empirical readers can read in many ways, and there is no law which tells them how to read, because they often use the text as a container for their own passions, which may come from outside the text, or which the text may arouse by chance" (ECO, 2005). Tradução do autor.
} 
o leitor a preencher espaços no campo semântico de acordo com suas próprias expectativas e também daquelas ligadas ao meio cultural em que ele tem sua origem. Partindo da afirmação "aquele homem vem de Baçorá", Eco afirma que

Endereçada a um habitante do Iraque, ela teria, mais ou menos, o mesmo efeito da frase sobre Milão ao italiano. Dita a uma pessoa absolutamente ignorante, que desconheça por completo a geografia, poderá deixá-la indiferente, ou quando muito curiosa [...]. Dita enfim a uma terceira pessoa, a menção a Baçorá poderia despertar imediatamente a lembrança, não de um local geográfico determinado, mas de um "lugar" do fantástico, conhecido através da leitura das Mil e Uma Noites. [...] Baçorá não constituirá um estímulo capaz de estabelecer uma referência imediata, com um significado preciso, mas provocará um "campo" de lembranças e sentimentos, a sensação de uma proveniência exótica, uma emoção complexa e esfumada em que conceitos indeterminados se misturam a sensações de mistério, indolência, magia, exotismo (ECO, 2000, p. 77).

Convém lembrar que a frase sobre Baçorá não difere formalmente, quer dirigida a um iraquiano ou a um imaginativo leitor europeu; suas variações de referencialidade, portanto, não residem "na expressão em si, mas no receptor" (ECO, 2000, p. 77). Citando Compagnon (1999) - que por sua vez toma como base o conceito de Proust -, “... não há leitura inocente, ou transparente: o leitor vai para o texto com suas próprias normas e valores." O sentido, para ele, “... não é mais um objeto a ser definido, mas o efeito a ser experimentado" (COMPAGNON, 1999).

Iser (2000, p. 102), por sua vez, compara a experiência da leitura à da interação diádica, no que diz respeito ao que ele chama de "negatividade da experiência", ou seja, a impossibilidade de experimentar a experiência do outro, e ao espaço de indeterminação que se cria a partir disso. Se nas relações interpessoais, porém, a comunicação pressupõe ações pragmáticas e, portanto, exige maior grau de determinação e um padrão de referências compartilhado pelos parceiros para que obtenha sucesso, "a assimetria de texto e leitor possui em princípio menor grau de determinação, e é essa falta de determinação que amplia as possibilidades de comunicação." Entretanto, "para que essas possibilidades se realizem e a comunicação entre texto e leitor tenha sucesso, é preciso que a atividade do leitor seja de alguma maneira controlada pelo texto" (ISER, 2000, p. 104). Tal controle está ligado ao estímulo proporcionado pelo próprio texto, a que nos referimos acima, aos atos de compreensão, a ler o que não está expresso no texto ${ }^{2}$. o que é

${ }^{2}$ Para ilustrar isso, Iser cita comentário de Virginia Woolf a respeito de Jane Austen: "She stimulates us to supply what is not there" (WOOLF apud ISER, 2000, p. 105). Cita, ainda, Merleau-Ponty, quando este afirma que: "a linguagem diz irrefutavelmente quando renuncia a dizer a coisa em si..." (MERLEAU-PONTY apud ISER, 2000, p. 107). 
silenciado pela narrativa, por razões de estratégia textual, estimula o leitor a ocupar as lacunas, os espaços vazios, com suas próprias projeções (ISER, 2000 , p. 106). Existe, porém, o risco do fracasso sempre que o leitor ocupa o vazio apenas com suas próprias projeções, sobrepondo-as ao texto sem que este lhes oponha resistência (ISER, 2000, p. 103). Para ser bem-sucedido, o texto deve provocar "uma multiplicidade de representações do leitor, pelas quais a assimetria dominante começa a ser dissolvida, dando lugar a uma situação comum a ambos os pólos da comunicação" (ISER, 2000, p. 104). Quando isto não se dá, quando o leitor se vê incapaz de superar esta assimetria, expandindo, ao mesmo tempo, seu horizonte de representações, ocorre o que Iser denomina de "fracasso do leitor".

Diante do exposto até aqui, creio já ser possível delimitar o objetivo deste artigo, o qual se disporá a analisar, tomando como ponto de partida os conceitos expostos brevemente acima, a obra O Mistério da Prostituta Japonesa, de Valêncio Xavier. Tentarei demonstrar que, no conto de Xavier, a dissonância entre o manifesto e o não expresso se vale do fracasso do leitor como estratégia comunicativa, criando algo que poderíamos denominar de "narrativa-espelho", em que o leitor pode ver no fracasso do narradorprotagonista em interpretar satisfatoriamente o mistério da prostituta, eternamente indeciso entre inserir as projeções de sua própria vontade no vazio expressivo da personagem ou aceitar que seu horizonte de representações não dá conta de chegar a um sentido inequívoco, posto que não existe tal possibilidade, uma narrativa-espelho em que o leitor pode ver, enfim, uma imagem de si próprio, e por meio dela compreender os sentidos gerados pelo texto.

\section{O FracASSO COMO ESTRATÉGIA NARRATIVA}

O conto O Mistério da Prostituta Japonesa, de Valêncio Xavier, foi publicado pela primeira vez em 1984, no n. ${ }^{\circ} 117$ da revista curitibana Quem, depois reunido ao conto Mimi-Nashi-Oishi em um pequeno volume publicado pela Gráfica \& Editora Módulo 3, em 1986, compondo o que poderíamos, talvez, chamar de "contos orientais" de Valêncio. Como outras narrativas publicadas pelo autor na década de 80 , foi republicado em 1998 pela editora Companhia das Letras, sob o título o Mez da Grippe e Outros Livros ${ }^{3}$. Em termos de enredo, pouca coisa é narrada além do encontro do personagemnarrador com a prostituta japonesa que dá título ao conto e sua despedida na saída do hotelzinho de rendez-vous em que se dá o affair (sabemos pelas notas incluídas por Xavier ao final da edição de 1998 que o evento se passa no bairro da Liberdade, em São Paulo). O que primeiro chama a atenção no conto é a precisão extremamente detalhista com que o protagonista-narrador

\footnotetext{
${ }^{3}$ As citações deste artigo serão extraídas da versão de 1986. Eventuais exceções serão assinaladas por notas.
} 
descreve o pequeno quarto em que se realiza o programa, chegando a extremos de exibir-se um desenho em que o ambiente é retratado com seus parcos elementos: uma escadinha de três degraus, uma cama de casal e uma mesinha de cabeceira, além de um conjunto de meias-paredes que divide o quarto em um ambiente ainda menor, o banheiro, dotado de pia, latrina e chuveiro. Também no banheiro, texto e desenho fazem referência a uma pequena janela basculante de frente para a entrada sem porta, cujo ângulo de visão incide diretamente sobre a cama. Já no primeiro parágrafo, quatro frases delimitam o espaço em que a maior parte da narrativa transcorrerá e estabelecem alguns dos principais elementos que irão compô-la: o quarto, o hotelzinho barato de rendez-vous, a escada de três degraus e a prostituta japonesa.

Convém observar a insistência com que o narrador se empenha em delimitar o espaço, reduzi-lo a proporções mínimas e subdividi-lo em frações ainda menores, com uma persistência de adjetivos e substantivos que reforçam a pequenez do espaço físico (o "pequeno quarto", o "cubículo sem portas" que forma o "minúsculo banheiro" etc.) e, provavelmente, da ação. Afinal, trata-se de um "hotelzinho de rendez-vous" (XAVIER, 1986, p. 5 ), em que prostitutas baratas levam seus clientes de programas, e isso certamente nos permite inferir que estamos diante de mais de um tipo de pequenez: a da exiguidade do espaço em que o sexo apressado do narrador com a prostituta japonesa é feito; a da sordidez do hotelzinho, que mais à frente veremos estar encravado entre outros hoteizinhos baratos em uma rua mal-afamada de um bairro de prostituição. Mas há também outras formas de pequenez que transparecem na preocupação obsessiva do narrador com os adjetivos que expressam inferioridade: a da baixeza moral, da mesquinharia e da torpeza, sentimentos associados à culpa que o narrador deixa transparecer quando se preocupa com o fato de que "Um olho pode estar à espreita. Deitado na cama, vejo diante de mim, através da abertura sem porta do pequeno banheiro, a janela basculante com falhas na pintura" (XAVIER, 1986, p. 6).

$\mathrm{Na}$ maior parte das vezes, porém, tal sentimento de culpa ou de estar fazendo algo que não deva ser visto por olhos indesejáveis não é expresso textualmente. Durante quase toda a narrativa, o protagonista limita-se a descrever, minuciosamente e de modo quase neutro, o espaço e a ação com precisão comparável à do cientista ao delimitar seu objeto de estudo. Todo o segundo parágrafo do conto parece empenhado em fazer com que o leitor componha uma imagem visual do pequeno quarto de encontros sexuais, com sua escadinha de três andares, sua cama de casal que ocupa a maior parte do espaço, seu piso de tacos de madeira cinza "muitas vezes lavado nunca encerado" (XAVIER, 1986, p. 5) e o cubículo que delimita o banheiro, a perfeita imagem da decadência, da exiguidade e da ausência de emotividade. O uso da palavra imagem aqui não é casual: há claramente 
uma intenção de que o leitor veja o espaço físico da narrativa, e o autor implícito usa de todos os meios possíveis para se assegurar de que isso ocorra, incluindo a apresentação de um desenho esquemático representando o quarto em seus elementos. Essa preocupação extrema com a meticulosidade da descrição tem um propósito razoavelmente claro: não estamos aqui diante de uma descrição destinada a evocar uma imagem hipotípica - condicionada, portanto, à capacidade de imaginação - na mente do leitor, mas sim da representação icônica de um quarto de hotel que seja um signo de todos os outros quartos de hotel barato em que se realizam encontros sexuais apressados.

Peirce (2003, p. 64), para quem "o pensamento é o principal, senão o único, modo de representação", identifica as imagens mentais como representâmens, como signos que substituem um objeto representado na mente de um interpretante. Ele define um ícone, entre os tipos de signos, afirmando que a "qualidade que ele tem qua coisa o torna apto a ser um representâmen. Assim, qualquer coisa é capaz de ser um substituto para qualquer coisa com a qual se assemelhe" (PEIRCE, 2003, p. 64). Um signo icônico é, portanto, "uma imagem de seu objeto e, em termos mais estritos, só pode ser uma idéia Interpretante, e um objeto externo excita uma idéia através de uma reação sobre o cérebro" (PEIRCE, 2003, p. 64). Peirce vai ainda um pouco além, ao estabelecer que "a única maneira de comunicar diretamente uma idéia é através de um ícone" (PEIRCE, 2003, p. 64, grifo meu). Xavier recorre a dois tipos de representação do espaço em seu conto: a descrição do quarto do hotel de rendez-vous, em que a reiteração dos adjetivos indicando seu tamanho reduzido, mencionada acima, contribui para que o leitor forme a ideia de sordidez e inferioridade; e o próprio ícone gráfico representando uma imagem do quarto. Assim, também, ocorre com os gestos da prostituta japonesa, que reproduzem de maneira exata - e muito pouco sedutora, é necessário que se diga - o que se esperaria de uma profissional como ela, sempre que recolhe um de seus fregueses para um hotelzinho do gênero: o caminho pelos corredores do lugar, o despir-se sem maiores cerimônias, o banho no compartimento exíguo que serve de banheiro, os comentários banais. Nenhum fracasso parece possível até aqui, o leitor pode caminhar em terreno sólido.

o mesmo não se pode dizer do personagem-narrador, perdido no espaço labiríntico do hotel às escuras, totalmente dependente da experiência da prostituta japonesa para se orientar entre os corredores e escadarias que é necessário percorrer para chegar à privacidade do quartinho exíguo:

Eu não saberia reconstituir o caminho que nos conduziu da portaria do hotelzinho barato até este pequeno quarto. Muitas vezes trilhadora do labirinto, a prostituta japonesa caminha adiante de mim pelos caminhos escuros. Por portas fechadas, um longo corredor estreito, o pequeno pátio mal iluminado pela noite, uma escadaria 
sobe à esquerda, depois à direita, outro negro corredor cortado em cruz por outro corredor sem luz, uma negra sala sem portas, talvez uma varanda. Como é escura esta noite sem estrelas! Um corredor de paredes sem portas e a porta do pequeno quarto. Não sei dizer a que parte do hotelzinho barato dá esta janela basculante (XAVIER, 1986, p. 6).

Mas também para o leitor as coisas começam a ficar menos sólidas a partir daqui. Aparentemente, Xavier decidiu conferir um alto grau de determinação ao espaço em que os personagens interagem, tornando-o facilmente reconhecível ou imaginável pelo leitor, ao mesmo tempo que dota a relação entre eles de intensa indeterminação. O primeiro indício que ele nos fornece da impenetrabilidade da prostituta japonesa é o fato de suas falas serem representadas em idioma japonês, com escrita ideogramática. Convém recorrermos aqui novamente a Peirce, uma vez que é evidente estarmos diante de outro tipo de signo. Segundo ele, "um Símbolo é um Representâmen cujo caráter representativo consiste exatamente em ser uma regra que determinará seu Interpretante" (PEIRCE, 2003, p. 71). Todas as palavras são símbolos, portanto, assim como todo tipo de signos convencionais. A escrita japonesa inserida no texto, porém, não é um símbolo da mesma natureza que o restante das palavras. Impossível não lembrarmos, aqui, daquele homem que nos chega de Baçorá no exemplo de Eco.

É adequado supor que a maioria dos leitores do conto de Valêncio Xavier não entenda japonês. Para os que entendem, as falas não passam de frases aparentemente banais, adequadas à situação representada: um alerta sobre os degraus no quarto às escuras, um elogio convencional à gentileza do homem, afirmações quase fáticas, enfim, o que aliás, mesmo para quem não entenda uma palavra de japonês, é possível deduzir. Mas há um aspecto que torna as frases mais intrigantes: embora o provável leitor modelo - e a maioria de nós, leitores empíricos - não consiga lê-las, em um sentido literal, para o personagem-narrador elas têm um sentido claro, corriqueiro até. Exemplo disso é seu comentário a uma das frases proferidas pela prostituta enquanto ela se banha: "E eu é que sei? Nunca estive antes neste hotel de rendez-vous." (XAVIER, 1986, p. 7). Por outro lado, não há nenhum indício de que estejamos diante de um personagem-narrador bilíngue, que entenda japonês. Ao contrário, a banalidade da situação e, principalmente, a última fala da personagem feminina, quando, para usar também uma frase feita, o encanto se desfaz e a prostituta profere em português a fórmula para recusar o convite do protagonista, "Fica para outra vez..." (XAVIER, 1986, p. 9), parece indicar o oposto. Podemos afirmar, portanto, com bastante segurança, que o fato de a prostituta "falar" em japonês para o leitor, mas não para o protagonista, deve-se a uma estratégia do autor implícito (optando pela denominação de Iser) para nos indicar o fato de que o protagonista projeta, desde o início, suas próprias expectativas no vazio expressivo da 
personagem. Como o homem de Baçorá, a prostituta oriental nos chega carregada de evocações de mistério, exotismo e submissão de gueixa, que o protagonista procura ao escolher uma meretriz japonesa e que o leitor é convidado a ler nos kanjis e hiraganas de suas frases.

Não estamos mais, portanto, diante de uma prostituta comum, como as tantas que povoam os pontos de prostituição das ruas das cidades, mas sim de uma personagem simbólica do exotismo sexual e da aura de mistério que nós ocidentais tendemos a atribuir ao oriente. É necessário, porém, admitir que isto é apenas em parte verdadeiro. As atitudes da prostituta, seus gestos, procedimentos, todo o seu modus operandi, não diferem em nada dos de qualquer outra prostituta de rua. O encontro sexual entre ela e o personagem-narrador é tão banal e sem atrativos quanto as frases que profere, e que só nos parecem carregadas de mistério porque somos - ao menos a maioria de nós - incapazes de decifrá-las ao pé da letra. Somos, por assim dizer, ludibriados por nossas expectativas de leitores ocidentais. Assim também o personagem-narrador se deixa levar por sua fantasia, reforçada pela indeterminação da prostituta japonesa, por sua incomunicabilidade, que talvez não passe de um indício da artificialidade do relacionamento de qualquer prostituta com seus clientes, sempre convencional, impessoal e regrado pela brevidade do tempo, mas a incapacidade do protagonista em avaliar sua parceira ("Difícil dizer a idade das mulheres orientais", diz ele (XAVIER, 1986, p. 7), como primeira manifestação dessa incapacidade) o leva a preencher o vazio do relacionamento forjado com o repertório de seu próprio desejo. Como René Gallimard, personagem da peça $M$. Butterfly, de David Henry Hwang (e também da adaptação cinematográfica homônima, dirigida pelo canadense David Cronemberg), que por vinte anos ama uma personagem inexistente senão como fruto de suas fantasias ocidentais, nosso narrador se deixa trair por seu próprio anseio de amor fantástico. Se o oficial diplomático Gallimard vê a personagem da ópera de Puccini na chinesa submissa criada por um ator-espião, fazendo dela sua amante, o protagonista do conto de Xavier, incapaz de compreender eficientemente a atitude da prostituta, ficará eternamente obcecado pela assimetria entre a superfície inerte e indiferente, quase cadavérica, da prostituta durante o ato sexual e a mobilidade de seu interior paradoxalmente impenetrável, ora preenchendo o vazio gerado por essa assimetria com sua própria vontade, ora tendendo a enxergá-lo com olhos de dúvida.

Convém aqui identificar o momento em que a armadilha interpretativa começa a se fechar sobre o narrador, logo que a prostituta japonesa se deita a seu lado: "Não fosse por um lento respirar, eu diria completamente imóvel. Contudo, me parece imóvel somente na superfície visível. Eu diria que por dentro dele existe toda uma mobilidade - tranqüila?" (XAVIER, 1986, p. 7). O protagonista intui, assim, a existência de um descompasso entre a exterioridade imóvel e indiferente da prostituta e a 
interioridade inatingível de seus sentimentos. É desse momento em diante que irá germinar a perplexidade insolúvel do personagem-narrador. Se existe tal descompasso, se a imobilidade análoga à morte é só exterior e se o interior não pode ser atingido senão por meio de indícios imprecisos, então constitui-se um vácuo de sentido a ser preenchido pela interpretação do protagonista. E é no momento que sucede o gozo, quando ele estará mais suscetível à fertilidade da fantasia e à sua fertilização pela dúvida, que veremos isso acontecer:

No beijo, encosto meu rosto no dela, mordisco sua orelha. Por instantes, não sinto mais o cheiro úmido da colcha de tecido brilhante, cor vermelha. O gozo me vem rápido. Mas permaneço ainda dentro de seu corpo. Quando retiro meu corpo, é para deitar ao lado dela, e meu travesseiro é seu seio esquerdo. Ela não disse nem um gemido, nem uma palavra. Se houve algum gemido, na hora do gozo, foi meu, não dela. Não sei o que ela sentiu. Permaneceu, permanece silenciosa e não sei para onde olha. Seu coração bate rápido e descompassado. Levanto a cabeça e olho para ela. Inquieto?

Nossa, teu coração está batendo tão esquisito?

- $[\text { Eu gozei }]^{4}$.

- Verdade?

- [De verdade, mesmo].

Não demonstrou. Será que ela diz a verdade? Fico só olhando. Eu diria que ela está completamente imóvel. Imóvel somente na superfície visível do corpo cor de chá, pele lisa sem pêlos, suave monte-de-vênus de parca penugem. Coração batendo forte, ela olha para onde não sei (XAVIER, 1986, 8).

É claro que o narrador não é ingênuo a ponto de aceitar a palavra da prostituta à primeira vista. Afinal, a confissão do gozo é uma das mentiras clássicas das prostitutas. Mas duas coisas contribuem para a sua dúvida. A primeira delas é a própria descontinuidade entre o corpo inerte da mulher e seu coração acelerado, indício de reação visceral após o coito. A outra é, novamente, a sugestão da indecifrabilidade e do mistério da ideia que o senso-comum ocidental faz do oriente, como no exemplo de Eco. Em sua dúvida, o narrador-personagem se pergunta: "Mas teria mesmo gozado? Não deu nenhuma demonstração, é difícil dizer numa mulher oriental." (XAVIER, 1986, p. 8). O protagonista é incapaz de chegar a uma conclusão e, por isso, preenche o vazio significativo da prostituta com sentidos próprios, apelando mesmo para um argumento sofismático para se convencer disso "Não é comum uma prostituta sentir prazer com um freguês", diz ele.

${ }^{4} \mathrm{O}$ texto entre colchetes contém uma tradução da fala da prostituta japonesa, que no original está escrito em idioma japonês. 
"Algumas fingem, ela não deu demonstração de nada" (XAVIER, 1986, p. 9) -; as prostitutas fingem o orgasmo, ela não reagiu, portanto não finge, portanto talvez tenha dito a verdade.

O terreno, por vezes pantanoso, da sexualidade humana é cenário frequente na ficção de Valêncio Xavier. Não é por acaso que o sexo é o ato escolhido aqui para expressar o fracasso do personagem do conto. o sexo pertence ao território da fantasia. Não se aplicaria também a ele a afirmação de Iser $(2000$, p. 101) de que "...reagimos como se conhecêssemos as experiências dos nossos parceiros; criamos sem cessar imagens de como os parceiros nos experienciam e agimos em seguida como se as nossas imagens fossem reais"? Se podemos nos fundir ao corpo do outro durante o coito é porque construímos uma imagem dele, tecemos nossas expectativas em torno dele, fazemos dele um espelho de nosso próprio corpo e somos para ele próprio também uma fantasia. Mas para o personagem-narrador do conto de Xavier, assim como para o necrófilo ou o amante de bonecas de sexshop, não existe troca, mas a inscrição da própria fantasia no corpo inerte que a aceita sem impor obstáculos, espaço vazio e totalmente permeável que é. Iser afirma também que “... a relação interpessoal assume traços patológicos à medida que os parceiros ocupam a lacuna da experiência com fantasias projetadas" (ISER, 2000, p. 101). O protagonista do conto não vê na relação com a prostituta japonesa senão a projeção incondicional de suas próprias expectativas. Neste caso, porém, ao contrário do que possa parecer à primeira vista, não é a fantasia sexual que está em jogo, pois não é o gozo rápido com a prostituta que seduz o protagonista para a sua armadilha interpretativa, mas sim a ambiguidade da oriental. Se seu corpo é passivamente permeável, seu interior é quase absolutamente impenetrável e só se deixa intuir por aquele movimento apenas perceptível pelo narrador, que unicamente se revela para que se instaure o mistério.

Aceitamos seu desconcerto porque ele é, em parte, também o nosso. $\mathrm{Na}$ situação extrema do seu fracasso, vemos a imagem refletida de nossa estratégia de leitores, tentados a preencher o vácuo de sentido do texto com o qual nos deparamos com nossas próprias projeções, sempre que nosso repertório não dá conta de resolver satisfatoriamente sua indeterminação. Não é assim, afinal, que lemos as falas quase indecifráveis da personagem do conto? Como quem fantasia sobre uma Baçorá que não existe senão em nossa imaginação de leitores ocidentais? É possível ler o fracasso do narrador porque ele reflete o próprio fracasso do leitor, que longe de ser um fator de ilegibilidade, é uma estratégia programada de produção de sentido. Xavier demonstra isso quando constrói esta narrativa em que o fracasso interpretativo e a consequente imposição de sentidos recolhidos do repertório cultural da tríade personagem-narrador-leitor é o principal fator de produção de sentido. Se o fracasso do protagonista se deve ao fato de ele construir uma imagem da prostituta japonesa amparada nas projeções de seu desejo 
mais do que na realidade demonstrada por ela - que, afinal, simplesmente se vai com sua companheira síria ou turca (ou de Baçorá, talvez?), deixandoo com sua dúvida, mas sem demonstrar nenhum afeto que a sustente -, o fracasso do leitor insinua-se já quando nos tentamos a preencher as lacunas dos diálogos da prostituta com nosso fantasiar sobre gueixas e madames butterflies, o que é exposto, vivissectado pela narrativa. Os versos de Desnot inscritos sobre o ícone da mão estendida em um apelo inútil (que na edição de 1998 se revestem de ainda outro sentido, pois os versos parecem escapar pelos dedos da mão implorante (XAVIER, 1998, p. 191) $)$, em que a sombra e o sonho tomam lugar da imagem real da pessoa sonhada, de modo que nada mais resta de real nela, são bastante significativos:

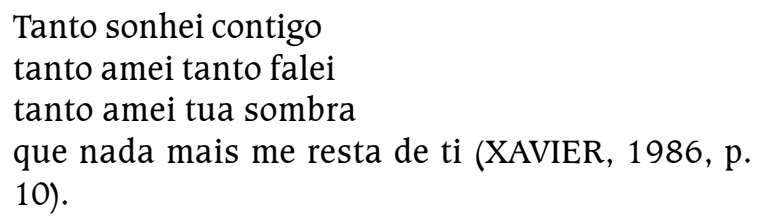

É nesse sentido que é possível afirmar que o conto O Mistério da Prostituta Japonesa, de Valêncio Xavier, é uma narrativa-espelho, ou seja, uma narrativa cuja estratégia de significação prevê a exposição das próprias estratégias de leitura a que o leitor recorre. Ela produz sentido porque vemos no fracasso do narrador e na maneira como ele constrói a própria armadilha em torno de si ao projetar sentidos próprios aos espaços vazios evocados pelo comportamento ambíguo da prostituta japonesa, um ícone de nossas estratégias de leitura. O protagonista de Xavier, que se perde numa busca sem final possível, entre inusitadas drogas que evocam delírios orientais (e é interessante o contraste oferecido pela referência à cocaína, droga de origem ocidental que só é adquirida na tentativa de conseguir uma informação que se revela inútil), é a própria imagem de tantos leitores como nós, leitores empíricos, que, como diz Eco, frequentemente usamos o texto como receptáculo de nossas próprias paixões, que podem até mesmo ser exteriores a ele, mas que por acaso ele pode despertar.

${ }^{5}$ As diferenças entre o desenho da edição de 1986 e o desta, aliás, dariam material suficiente para mais um artigo sobre o conto de Xavier. 


\title{
RESUMO
}

O objetivo deste artigo é analisar as estratégias de produção de sentido usadas por Valêncio Xavier em seu conto O Mistério da Prostituta Japonesa. Para tanto, recorre a conceitos como o dos espaços vazios da narrativa, de Iser, e o do consequente fracasso do leitor diante da incapacidade de superar a assimetria entre seu horizonte de referências e correferências e o nível de determinação do texto, resultando na ocupação dos vazios do texto unicamente com suas próprias projeções (ISER, 2000). Também recorre ao conceito de obra aberta de Umberto Eco (2000), particularmente no que diz respeito à ocupação dos espaços no campo semântico do texto pelas expectativas do leitor, incluindo aquelas ligadas ao meio cultural em que ele se origina. O conto de Xavier pode ser visto, sob esse prisma, como uma narrativa-espelho, em que o leitor vê no fracasso do personagem-narrador em interpretar a assimetria entre a superfície inerte da prostituta japonesa que dá título ao conto e seu interior aparentemente movediço, fracasso que é ao mesmo tempo originado e preenchido por suas expectativas culturais relacionadas à mulher oriental, uma imagem de suas próprias estratégias de leitura e geração de sentido a partir do texto.

Palavras-chave: recepção; leitura; teoria do efeito estético; Valêncio Xavier.

\begin{abstract}
The aim of this article is to analyze the meaning-producing strategies used by Valêncio Xavier in his short-story O Mistério da Prostituta Japonesa. Thus, it appeals to some concepts, such as the existence of empty spaces in the narrative, as described by Iser, and the consequent failure of the reader before the impossibility to overcome the asymmetry between his own reference and co-reference horizon and the levels of determination of the text, which results in the act of filling those textual gaps only with one's own projections (ISER, 2000). It also recurs to Umberto Eco's (2000) concept of open work, specially referring to the filling of the semantic field of the text by the expectations of the reader, including those expectations attached to his original cultural environment. Xavier's shortstory can be interpreted, according to this point of view, as a mirror-narrative, in which the reader can see in the failure of
\end{abstract}


the narrator-character in interpreting the asymmetry between the still surface of the Japanese whore who entitles the tale, and the apparently moving deep interior of hers, a failure that is simultaneously originated from and filled by his cultural expectations related to Oriental women, an image of reader's strategies of reading and generating meanings from the text. Keywords: reception; reading; aesthetic theory of effect; Valêncio Xavier.

\section{REFERÊNCIAS}

COMPAGNON, Antoine. O demônio da teoria: literatura e senso comum. Belo Horizonte: Editora UFMG, 1999.

ECO, Umberto. The author and his interpreters. Disponível em: <http:// www.themodernworld.com/eco/eco_author.html>. Acesso em: 06/08/2005. . Obra aberta. 8. ed. São Paulo: Perspectiva, 2000.

. Pós-escrito a o nome da rosa. Rio de Janeiro: Nova Fronteira, 2000.

ISER, Wolfgang. $O$ ato da leitura: uma teoria do efeito estético. São Paulo: Editora 34, 2000. v. 2.

JOUVE, Vincent. A leitura. São Paulo: Editora UNESP, 2002.

PEIRCE, Charles Sanders. Semiótica. 3. ed. São Paulo: Perspectiva, 2003.

XAVIER, Valêncio. O mez da grippe e outros livros. São Paulo: Companhia das Letras, 1998. . O mistério da prostituta japonesa \& Mimi-Nashi-Oishi. Curitiba: Gráfica \& Editora Módulo 3, 1986.

Submetido em: 28/02/2008.

Aceito em: 07/07/2009. 